\title{
Part-set cuing of false memories
}

\author{
MATTHEW B. REYSEN and JAMES S. NAIRNE \\ Purdue University, West Lafayette, Indiana
}

\begin{abstract}
Part-set cuing inhibition describes the common finding that re-presenting items from a word list can reduce subjects' overall recall performance for studied items. Do part-set cuing effects occur for false memories as well? In the present experiments, subjects studied lists of words drawn from Roediger and McDermott (1995). After studying each list, subjects completed math problems and then recalled the list items either with or without accompanying list cues. In Experiment 1, the recall cues consisted of items drawn randomly from the original list. In Experiment 2, an additional type of cued recall task was added in which the even numbered list items were used as cues. Taken together, these experiments demonstrate robust part-set cuing effects for critical nonpresented items. In addition, they show that whereas recall of critical words is reduced by the presence of cues at test, retrieval cues do not affect critical words and studied words in exactly the same manner.
\end{abstract}

Since Roediger and McDermott's (1995) experiments revived interest in Deese's (1959) false memory paradigm, false memories have been examined in a number of studies using variations of these researchers' procedure. While many have manipulated aspects of the study material such as the number of associates (Roediger, Balota, \& Robinson, 2001) and presentation rate (Toglia \& Neuschatz, 1996), a few have manipulated test time variables such as delay (Basden, Reysen, \& Basden, 2002) and divided attention (Payne, Lampinen, \& Cordero, 1996). In the present experiments, we examined the effect of another test time variable, the presence or absence of cues at the point of recall, on subjects' memory for nonpresented critical words. In particular, we sought to determine whether we would observe part-set cuing of false memories.

\section{Part-Set Cuing Inhibition}

Part-set cuing inhibition occurs when subjects recall fewer list items as a result of presenting a portion of the tobe-remembered information at the point of test. Subjects provided with some of the original list items at test often recall fewer items, on the average, than do subjects provided with no cues at all. This finding is counterintuitive, in the sense that list-based retrieval cues might be expected to facilitate recall consistently. Part-set cuing provides a clear demonstration of how a test time variable can influence subjects' memory for word lists; the effect is robust, having been observed with noncategorized lists (see, e.g., Roediger, Stellon, \& Tulving, 1977; Slamecka, 1968 ) as well as categorized lists (e.g., Basden \& Basden, 1995; Tulving \& Pearlstone, 1966). Furthermore,

Correspondence concerning this article should be addressed to J. S. Nairne, Department of Psychological Sciences, 1364 Psychological Sciences Building, Purdue University, West Lafayette, IN 47907-1364 (e-mail: nairne@psych.purdue.edu). researchers have manipulated a number of variables, such as the number of cues provided at test (e.g., Hudson \& Davis, 1972) and the type of cues provided-for example, category names (e.g., Pollio \& Gerow, 1968) and category instances (e.g., Bellezza \& Hartwell, 1981). The primary finding from the many part-set cuing studies performed to date is that providing subjects with retrieval cues at test often hinders recall performance.

While a number of explanations have been provided for the part-set cuing effect (examples include the editing task hypothesis, Roediger \& Tulving, 1974; the cue overload hypothesis, Mueller \& Watkins, 1977; and the competition at retrieval hypothesis, Rundus, 1973), perhaps the most popular current account is the strategydisruption hypothesis (Basden \& Basden, 1995; Brown \& Hall, 1979; Slamecka, 1969). According to this view, a subject's preferred recall strategy can be disrupted by the presence of cues at the point of test. In effect, subjects use the externally provided cues, rather than internally generated cues, to direct the course of retrieval. External cue reliance leads to a less than optimal retrieval strategy and to reduced recall output. We explored a particular prediction of this account in Experiment 2.

\section{The Deese/Roediger-McDermott Paradigm}

We were mainly interested in examining how part-set cues, presented at test, would affect the recall of nonpresented items - specifically, the critical items drawn from the experiments of Roediger and McDermott (1995). Recent interest in laboratory-induced false memories can be traced to Roediger and McDermott's (1995) reexamination of Deese's (1959) false memory experiments. Deese's basic procedure involved presenting subjects with lists of semantic associates (e.g., thread, pin, eye, sewing, etc.) and subsequently measuring subjects' recall of those lists. Deese observed that subjects often recalled highly related but nonpresented critical words (e.g., needle). Using Deese's best lists (those that produced the greatest num- 
ber of intrusions), Roediger and McDermott replicated Deese's observation of high levels of false recall of nonpresented critical words. In addition, they extended Deese's original design to include measures of recognition and phenomenological experience. Roediger and McDermott observed high levels of false recognition for nonpresented critical words, and they also found that subjects often claimed to consciously recollect experiencing the critical words (but see Read, 1996). Thus, as Roediger and McDermott noted, subjects claimed to explicitly remember events that never occurred.

In the present experiments, we were interested in whether the presence of list cues at the point of test would inhibit or reduce the recall of nonpresented critical words. Our subjects studied lists of words drawn from Roediger and McDermott's (1995) study. After studying each list, the subjects completed math problems and then recalled the list items either with or without the presence of accompanying list cues. In Experiment 1, the test cues consisted of items drawn randomly from the original list. In Experiment 2, an additional type of cued recall task was added in which the even numbered list items were used as cues. By manipulating the presence or absence of cues at the point of test, we hoped to test prevailing accounts of false memory phenomena, particularly studied-based and retrieval-based implicit activation accounts. Taken together, these experiments demonstrate robust part-set cuing effects for critical words. In addition, they show that whereas recall of critical words is reduced by the presence of cues at test, retrieval cues do not affect critical words and studied words in the same manner.

\section{EXPERIMENT 1}

In Experiment 1, subjects were presented with sixteen 12-item lists. After studying each list, the subjects solved simple math problems for $15 \mathrm{sec}$ and then completed either a free or a cued recall test. On the cued recall tests, the subjects were presented with a random half of the original list items arranged in a new random order. During these tests, the subject's task was to recall as many of the remaining list items as possible. Again, we were primarily interested in determining whether retrieval cues would inhibit recall of nonpresented critical words.

\section{Method}

Subjects. Sixty-two Purdue University undergraduate psychology students participated in partial fulfillment of course requirements.

Materials and Design. The subjects studied sixteen 12-item word lists drawn from Roediger and McDermott's (1995) experiments. The items within each list were presented visually in descending order of associative strength. The items were individually presented at a rate of $1.5 \mathrm{sec}$ per word. Following presentation of each list, the subjects solved simple addition and subtraction problems for $15 \mathrm{sec}$ before completing either a free recall task or a cued recall task. During the free recall task, the subjects were asked to type as many words from the list as they could remember. During the cued recall task, 6 of the list items were displayed in a column on the monitor and the subjects were asked to type as many of the remaining list items as possible. The cues were chosen randomly from the original 12-item list and were displayed in a random order. The order of presentation for lists, as well as list type (cued vs. uncued), was determined randomly for each subject. Both the free recall task and the cued recall task were self-paced. When a subject pressed the "enter" key twice, indicating that he/she could no longer recall items from a list, the next list was displayed and the sequence of (1) list presentation, (2) math problems, and (3) cued or uncued recall test was repeated until the subject had been tested over all 16 lists. For 8 of the lists, cues were provided on the recall test, and for the other 8 lists, cues were not provided. Prior to beginning the experimental trials, each subject completed two practice trials-one with cues, one without.

Procedure. Each subject was informed that she/he would be watching some lists of words appear on the computer screen. The subjects were instructed to say each word aloud as it appeared on the screen. They were also told that, following each list presentation, they would be asked to solve some simple addition and subtraction problems. After they had solved these problems, the subjects were told that they would be asked to recall the list.

The instructions made clear that the subjects would sometimes be asked to recall all of the words from the list. The subjects were also told that at other times, some of the words from the list would be re-presented and that when this occurred, their task was to recall as many of the remaining list items as possible. After completing 2 practice trials, each subject completed 16 experimental trials, comprising the 8 cued trials and the 8 uncued trials.

\section{Results and Discussion}

An alpha level of .05 was adopted for all statistical analyses. First, the mean proportion of the nonpresented critical words recalled on the free recall tests $(M=.41)$ was similar to the levels of false memory observed in other experiments employing similar methods (e.g., $M=$ .40; Roediger \& McDermott, 1995). Thus, we replicated the commonly observed false memory effect. Second, we observed a part-set cuing effect for the studied words. The subjects recalled a higher proportion of studied words on free recall tests $(M=.51)$ than on cued recall tests $(M=.45)$. A paired samples $t$ test conducted on the proportion of studied words recalled revealed that this effect was reliable $[t(61)=4.90, p<.05] .^{1}$

The primary purpose of Experiment 1 was to determine whether the presence of cues at the point of recall would inhibit false memory (i.e., a part-set cuing effect for false memories). A repeated measures ANOVA contrasting test condition (free recall vs. cued recall) with item type (studied vs. critical) revealed main effects for both of those variables. The subjects tended to recall a greater proportion of words on free recall tests than on cued recall tests $\left[F(1,61)=39.50, M S_{\mathrm{e}}=.015\right]$ and tended to recall a greater proportion of studied words than of critical words $\left[F(1,61)=41.80, M S_{\mathrm{e}}=.031\right]$. The interaction between test condition and item type was also statistically significant $\left[F(1,61)=6.78, M S_{\mathrm{e}}=.017\right]$. Notably, the subjects recalled a higher proportion of critical words on free recall tests $(M=.41)$ than on cued recall tests $(M=.26)$; planned comparisons conducted on the critical words revealed a reliable difference $[t(61)=$ $4.71, p<.05]$. Thus, we observed part-set cuing effects for nonpresented critical words, and, interestingly, the 
cuing effect was larger for the critical words than for the studied words.

\section{EXPERIMENT 2}

Having obtained a part-set cuing effect for false memories, we next sought to determine whether the part-set cuing effect for studied words and critical words depends on the nature of the cues provided at test. Specifically, we were interested in testing a prediction of the "strategydisruption hypothesis" that presenting consistent retrieval cues affects the size and extent of the part-set cuing effect. Consistent cues are simply cues that are congruent with a subject's favored retrieval strategy. According to the strategy disruption hypothesis, consistent (i.e., less disruptive) retrieval cues can reduce or eliminate the standard part-set cuing effect for studied words. This prediction has been substantiated in previous research (Basden \& Basden, 1995; Sloman, Bower, \& Rohrer, 1991). At issue, of course, is whether a similar outcome will occur in the recall of critical nonpresented words.

It is widely believed that subjects use seriation strategies in recall-that is, they often attempt to recall items in the order in which they have been presented (see Nairne, Riegler, \& Serra, 1991). If so, then providing that subject with every other item in the list (i.e., the even numbered list items) should facilitate recall because the cues would be consistent with an ordered recall strategy (see Sloman et al., 1991). Experiment 2 followed the procedures of Experiment 1, except for the addition of a condition in which subjects were asked to recall lists in the presence of consistent cues. These cues comprised the even numbered list items from the original 12-item list.

\section{Method}

Subjects. Eighty-four Purdue University undergraduate psychology students participated in Experiment 2. The results obtained from 2 subjects were excluded, because those subjects failed to complete the experiment.

Materials and Design. The design of Experiment 2 was identical to that of Experiment 1, with two exceptions. First, a new cued recall condition was added in which the subjects were cued with the even numbered list items rather than with random cues. Second, as a result of this change, eighteen 12-item lists were used in Experiment 2 . The subjects completed 6 free recall tests, 6 cued recall tests with random cues, and 6 cued recall tests with the even numbered list items used as cues. Prior to beginning the experimental trials, each subject completed two practice trials-one with random cues, one without cues.

Procedure. With the exception of the number of lists used, the procedure in Experiment 2 was identical to that in Experiment 1.

\section{Results and Discussion}

The mean proportions of studied words and critical words recalled are displayed in Table 1. As expected, the subjects recalled a high proportion of nonpresented critical words in the free recall condition $(M=.41)$. This observation is consistent with the results obtained by other researchers examining false recall in the Deese/Roediger-
Table 1

Proportions of Critical Words and Studied Words Recalled in Experiment 2

\begin{tabular}{clc}
\hline Item Type & Condition & Proportion \\
\hline Critical words & Free recall & .41 \\
& Cued recall & \\
& Consistent cues & .21 \\
& Random cues & .23 \\
Studied words & Free recall & .50 \\
& Cued recall & .44 \\
& Consistent cues & .40 \\
\hline
\end{tabular}

McDermott paradigm (e.g., Roediger \& McDermott, 1995), and it replicates the findings of Experiment 1. A repeated measures ANOVA revealed main effects of test condition $\left[F(2,162)=61.91, M S_{\mathrm{e}}=.016\right]$ and of item type $\left[F(1,81)=63.07, M S_{\mathrm{e}}=.051\right]$. The subjects recalled a greater proportion of words on free recall tests than on cued recall tests, and recalled a greater proportion of studied words than of critical words. Furthermore, the interaction between test condition and item type was also statistically significant $\left[F(2,162)=12.17, M S_{\mathrm{e}}=.019\right]$. As in Experiment 1, the cuing effect was larger, overall, for critical words than for studied words.

Clearly, we replicated the part-set cuing effect for critical words observed in Experiment 1. The subjects recalled a greater proportion of critical words in the free recall condition $(M=.41)$ than in either the consistent cue condition $(M=.21)$ or the random cue condition $(M=.23)$. Planned comparisons contrasting the free recall condition with both the consistent cue condition and the random cue condition revealed that these differences were statistically reliable $[t(81)=7.35, p<.05$, and $t(81)=$ $6.86, p<.05$, respectively]. However, importantly, the consistency of the retrieval cues had no effect on subject recall of critical words. Both random cues and consistent cues inhibited false memory to the same extent $[t(81)=$ $.98, p>.33$ ].

The results obtained for studied words revealed a somewhat different pattern. As expected, we replicated the part-set cuing effect for studied words observed in Experiment 1 . The subjects recalled a greater proportion of studied words in the free recall condition $(M=.50)$ than in either the consistent cue condition $(M=.44)$ or the random cue condition $(M=.40)$. Planned comparisons contrasting the free recall condition with both the consistent cue condition and the random cue condition revealed that these effects were reliable $[t(81)=5.15, p<$ .05 , and $t(81)=8.12, p<.05$, respectively]. However, unlike what was found for critical words, the consistency of the retrieval cues had a significant effect on recall for studied words. The subjects recalled a greater proportion of studied words in the consistent cue condition than in the random cue condition $[t(81)=2.68, p<.052] .{ }^{2}$ This finding is consistent with predictions based on the strategy disruption hypothesis suggesting that consistent cues can reduce part-set cuing effects for studied words. 
The results obtained in Experiment 2 highlight two main points of interest. First, we replicated the robust part-set cuing effect for critical words observed in Experiment 1 . Second, we found that critical words did not behave like studied words in our part-set cuing paradigm. Instead, subjects' memory for critical words was inhibited to the same extent, regardless of the consistency of the retrieval cues presented at the point of recall. We will further examine the implications of this finding below.

\section{GENERAL DISCUSSION}

Part-set cuing inhibition describes the common finding that re-presenting items from a word list can reduce subjects' overall recall performance (see Nickerson, 1984; Slamecka, 1968). In the present experiments, we have provided convincing evidence that robust part-set cuing effects occur for nonpresented critical words (false memories) as well as for studied words. Although this finding is interesting in its own right, we have demonstrated further that critical words may behave somewhat differently from studied words. Although the effects of part-set cuing can be reduced for studied words by manipulating the consistency of the retrieval cues (i.e., providing cues consistent with a subject's retrieval strategy), such a manipulation apparently has no effect on the recall of critical words.

The overall pattern seems to place important constraints on theories of false recall in the Deese/RoedigerMcDermott paradigm. For example, one popular account assumes that people implicitly "activate" critical nonpresented items, during either study or test, and thus recall or recognize the items as having occurred. The fact that people often claim to "remember" a critical item's occurrence (as opposed to just "knowing" that it has occurred) supports accounts of this type (see Roediger \& McDermott, 1995). According to a study-based implicit activation account, any manipulation that disrupts the subject's overall retrieval strategy might be expected to affect recall of both the critical and studied items; that is, one would predict part-set cuing for the critical items. Of course, this conclusion rests on the assumption that the critical items have been activated at study and that the subject will fail to discriminate their internal origin (e.g., Hicks \& Marsh, 1999). At the same time, it is clear from the data of Experiment 2 that critical nonpresented items do not behave like studied items. Presenting consistent cues reduced the part-set cuing effect for the studied items, but not for the critical words. Thus, if critical items are activated at study, they do not behave in a manner similar to that for list items. Data from other laboratories support this conclusion as well; for instance, repetition affects the recognition of critical and studied items in somewhat different ways (e.g., Tussing \& Greene, 1999).

According to the retrieval-based activation account, subjects internally "activate" the critical items during test. Critical items tend to be recalled near the end of the recall period (Roediger \& McDermott, 1995), which is at least consistent with this proposal. However, this kind of retrieval-based implicitly activated recall account has difficulty explaining the part-set cuing effects found in our experiments. Presenting half of the studied items at test should increase the chances of the subject's activating the critical items because more associative information, on average, should be available in the cued conditions. Yet, of course, recall of the critical items was reduced substantially. This result seems inconsistent with any simple retrieval-based implicitly activated recall account.

Moreover, for Experiment 2, we calculated the mean output position for the critical item in the free and cued recall conditions. Because the subjects recalled more items in the free recall condition, we calculated a ratio comparing the output position for the critical item in a given condition and the mean number of items recalled overall in that condition (for lists in which a critical item was recalled). Thus, the closer the ratio was to one, the later the item was output, on the average, during recall. For free recall, the ratio was 0.67 , whereas it was 0.83 and 0.75 for the random and consistent cuing conditions, respectively. These data suggest that the subjects tend to recall the critical item somewhat later in output when given cues at test; and this pattern, again, seems inconsistent with a retrieval-based implicit activation account unless it is only the act of recall itself that leads to activation. Furthermore, in this scenario, the subjects should have recalled more critical items in the consistent cue condition than in the random cue condition, yet no significant differences were found between these two conditions. Given these difficulties with a retrieval-based activation account, another explanation is needed.

One possible explanation is that the presence of cues at test might help to reinstate the original encoding context. This may enable people to more effectively monitor the source of an activated item-internal or external - and therefore exclude the nonpresented items at test. Such an account predicts a part-set cuing effect for the critical items: People would fail to recall the critical item because they possessed a heightened ability to differentiate between veridical and false memories. In addition, this account explains why the consistency of the cues at test might selectively affect recall. Whereas the presence of part-list cues impairs the recall of studied items, because of retrieval strategy disruption, the locus of the "impairment" for critical words lies in source monitoring. The consistency of the cues at test should therefore affect the cuing effect for studied words, but not for the critical words. Such a pattern, of course, was obtained in Experiment 2.

\section{REFERENCES}

BAsden, D. R., \& Basden, B. H. (1995). Some tests of the strategy disruption interpretation of part-list cuing inhibition. Journal of Experimental Psychology: Learning, Memory, \& Cognition, 21, 16561669.

Basden, B. H., Reysen, M. B., \& Basden, D. R. (2002). Transmitting false memories in social groups. American Journal of Psychology, 115, 211-231.

Bellezza, F. S., \& Hartwell, T. C. (1981). Cuing subjective units. Journal of Psychology, 107, 209-218.

Brown, A. S., \& Hall, L. A. (1979). Part-list cuing inhibition in se- 
mantic memory structures. American Journal of Psychology, 92, 351-362.

DEESE, J. (1959). On the prediction of occurrence of particular verbal intrusions in immediate recall. Journal of Experimental Psychology, 58, 17-22.

Hicks, J. L., \& Marsh, R. L. (1999). Attempts to reduce the incidence of false recall with source monitoring. Journal of Experimental Psychology: Learning, Memory, \& Cognition, 25, 1195-1209.

Hudson, R. L., \& DAvis, J. L. (1972). The effect of intralist cues, extralist cues, and category names on categorized recall. Psychonomic Science, 29, 71-75.

Mueller, C. W., \& Watkins, M. J. (1977). Inhibition from part-set cuing: A cue-overload interpretation. Journal of Verbal Learning \& Verbal Behavior, 16, 699-709.

Nairne, J. S., Riegler, G. L., \& Serra, M. (1991). Dissociative effects of generation on item and order retention. Journal of Experimental Psychology: Learning, Memory, \& Cognition, 17, 702-709.

Nickerson, R. S. (1984). Retrieval inhibition from part-set cuing: A persisting enigma in memory research. Memory \& Cognition, 12, 531-552.

Payne, D. G., Lampinen, J. M., \& Cordero, M. L. (1996, November 2). Remembrances of things not passed: Further evidence concerning false memories. Poster presented at the 37th Annual Meeting of the Psychonomic Society, Chicago.

Pollio, H. R., \& Gerow, J. R. (1968). The role of rules in recall. American Journal of Psychology, 81, 303-313.

READ, J. D. (1996). From a passing thought to a false memory in 2 minutes: Confusing real and illusory events. Psychonomic Bulletin \& Review, 3, 105-111.

Roediger, H. L., III, Balota, D., \& Robinson, K. (2001). Spreading activation and the arousal of false memories. In H. L. Roediger III, J. S. Nairne, I. Neath, \& A. Surprenant (Eds.), The nature of remembering: Essays in honor of Robert G. Crowder. Washington, DC: American Psychological Association.

Roediger, H. L., III, \& McDermott, K. B. (1995). Creating false memories: Remembering words not presented in lists. Journal of Experimental Psychology: Learning, Memory, \& Cognition, 21, 803-814.
Roediger, H. L., III, Stellon, C. C., \& Tulving, E. (1977). Inhibition from part-list cues and rate of recall. Journal of Experimental Psychology: Human Learning \& Memory, 3, 174-188.

Roediger, H. L., III, \& Tulving, E. (1974, May). Part-list cuing and directed forgetting. Paper presented at the meeting of the Midwestern Psychological Association, Chicago.

Rundus, D. (1973). Negative effects of using list items as recall cues. Journal of Verbal Learning \& Verbal Behavior, 12, 43-50.

SlamecKa, N. J. (1968). An examination of trace storage in free recall. Journal of Experimental Psychology, 76, 540-513.

SlameCKA, N. J. (1969). Testing for associative storage in multitrial free recall. Journal of Experimental Psychology, 81, 557-560.

Sloman, S. A., Bower, G. H., \& Rohrer D. (1991). Congruency effects in part-list cuing inhibition. Journal of Experimental Psychology: Learning, Memory, \& Cognition, 17, 974-982.

Toglia, M. P., \& Neuschatz, J. S. (1996, October 31) False memories: Where does encoding opportunity fit into the equation? Poster presented at the 37th Annual Meeting of the Psychonomic Society, Chicago.

Tulving, E., \& Pearlstone, Z (1966). Availability versus accessibility of information in memory for words. Journal of Verbal Learning \& Verbal Behavior, 5, 381-391.

Tussing, A. A., \& Greene, R. L. (1999). Differential effects of repetition on true and false recognition. Journal of Memory \& Language, 40, 520-533.

\section{NOTES}

1. The proportion of items recalled was scaled for the different number of possible recallable items for part-set lists vs. free recall lists.

2. We also checked the interaction contrast between item type and just the two cued-recall conditions (consistent vs. random without including free recall); the interaction met, but did not fall below, the conventional significance level $F(1,81)=3.91, M S_{\mathrm{e}}=.019, p=.05$.

(Manuscript received May 2, 2000; revision accepted for publication June 7, 2001.) 